\title{
COMPARTIMENTAÇÃO GEOMORFOLÓGICA DA BACIA HIDROGRÁFICA DO RIO ITU - OESTE DO RIO GRANDE DO SUL - BRASIL
}

\author{
Geomorphological Compartmentation the Itu River Basin - West of Rio Grande do Sul - Brazil
}

\author{
Romario Trentin \\ Prof. Adjunto, Universidade Federal de Santa Maria - UFSM \\ tocogeo@yahoo.com.br \\ Leonardo José Cordeiro Santos \\ Prof. Adjunto, Universidade Federal do Paraná-UFPR. Bolsista CNPq \\ santos@ufpr.br \\ Luís Eduardo de Souza Robaina \\ Prof. Associado, UFSM. Bolsista CNPq \\ lesrobaina@yahoo.com.br
}

Artigo recebido em 29/12/2011 e aceito para publicação em 12/04/2012

RESUMO: A geomorfologia utiliza a identificação das formas de relevo, por meio de estudo de sua origem, estrutura, natureza das rochas, clima e dos fatores endógenos e exógenos responsáveis pelo modelado ou formação de determinados elementos da superfície terrestre. Neste sentido, estabeleceu-se uma proposta de compartimentação geomorfológica da bacia hidrográfica do Rio Itu. Como base metodológica do trabalho, utilizou-se a proposta de Ross (1990, 1992), os mapas e as discussões apresentadas por Robaina et. al (2010) no estudo da bacia hidrográfica do Rio Ibicui. No levantamento cartográfico, adotaram-se cartas topográficas 1:50.000, imagens de satélite e trabalhos de campo. Foram determinados os atributos da rede de drenagem, as características do relevo, o substrato geológico e os tipos de solos. A integração dos dados e a compilação dos mapas permitiram a definição dos diferentes níveis taxonômicos. Nos três primeiros níveis de compartimentação, utilizou-se, como base, a bacia hidrográfica do Rio Ibicuí. A partir do quarto nível taxonômico, estabeleceram-se as unidades geomorfológicas especificamente para a bacia hidrográfica do Rio Itu (BHRI), onde foram definidas oito unidades de formas de relevo: Colinas de arenito, Morrotes de arenito, Cornijas de arenito, Rampa alúvio colúvio, Colinas vulcânicas de topo plano, Relevo escarpado, Morrotes de rocha vulcânica e Colinas de rocha vulcânica. No quinto e sexto níveis, são apresentadas as formas das vertentes e as feições características das unidades de relevo, sendo mais frequentes as curvaturas retilíneo-convergentes e as feições de areiais e voçorocas. A análise geomorfológica apresenta elementos fundamentais ao gerenciamento do meio e, portanto, é uma ferramenta indispensável ao planejamento ambiental.

Palavras chaves: Compartimentação geomorfológica, Bacia Hidrográfica, Voçorocas, Areais

ABSTRACT: The geomorphology is used to identify the forms of relief, through a study of its origin, structure, nature of the rocks, and climate of endogenous and exogenous factors responsible for the formation of patterned or certain elements of the earth's surface. In this sense, it was established a proposal for compartmentation the geomorphological Itu River basin. As a methodological basis of the work, we used the proposed Ross (1990, 1992), maps and discussions presented by Robaina et. al (2010) Ibicuí River basin. In mapping used topographic maps 1:50.000, satellite images and fieldwork. There were certain attributes of the 
drainage network, the terrain characteristics, the geological substrate and soil types. The integration of data and compilation of maps allowed the definition of different taxonomic levels. In the first three levels of compartmentation was used as the basis Ibicuí River basin. From the fourth level taxonomic settled geomorphological units specifically for the Itu River basin (BHRI), which defined eight units of landforms: hills of sandstone, sandstone hillock, sandstone cornices, Ramp alluvial colluvium, flat-topped volcanic hills, steep terrain, hillock hills of volcanic rock and volcanic rock. In the fifth and sixth levels are presented, the shapes of the sections and the distinctive features of the landscape units, being more frequent bends straight-convergent and features sand and voçorrocas. The geomorphological analysis presents the key elements to managing the environment and, therefore, is an indispensable tool for environmental planning.

Key words: Compartmentation geomorphological, Watershed, Gullies, Sands

\section{INTRODUÇÃO}

O estudo das formas de relevo se apresenta como objeto de estudo da Geomorfologia, tanto nos aspectos de gênese como evolução destas formas. Embora o relevo, numa rápida observação, pareça ser um componente estático do meio, ele está em constante processo de evolução, com velocidades variadas, interagindo, a todo instante, com os demais componentes da paisagem.

Dando suporte às análises geomorfológicas, a cartografia-geomorfológica é um dos mais importantes veículos de comunicação e análise dos resultados, obtidos nos estudos das formas e da compartimentação do relevo (LUPINACCI, MENDES e SANCHEZ, 2003).

As formas de relevo não são componentes independentes na paisagem e, consequentemente, a sua evolução também não é. Quando se pretende entender a evolução da forma de relevo de uma determinada área, torna-se necessário considerar as características geológicas, climáticas, hidrológicas, pedológicas e biológicas da respectiva área, bem como a atuação antrópica, pois o homem também é um componente do meio e um agente modificador de extrema atuação.

Conforme Penteado-Orelhana (1985), a análise geomorfológica consiste na identificação das formas de relevo, por meio de estudo de sua origem, estrutura, natureza das rochas, clima e dos fatores endógenos e exógenos responsáveis pelo modelado ou pela formação de determinados elementos da superfície terrestre.

Desta forma, os estudos geomorfológicos podem contribuir no planejamento e na conservação dos recursos naturais, estabelecendo formas racionais de uso destes recursos, sem alterar bruscamente o equi- líbrio do ecossistema. Estes estudos permitiram ainda a análise espaço-temporal dos processos atuantes no modelado do relevo terrestre, possibilitando a identificação ou a prevenção de processos de degradação ambiental que se achem relacionados aos elementos físicos. Desta maneira, a análise geomorfológica insere-se nos estudos ambientais, contribuindo, por seu turno, para orientar a instalação das atividades humanas (CHRISTOFOLETTI, 2001).

Dentro desse contexto, a geomorfologia fornece-nos uma visão integrada do meio físico, pois considera as variáveis responsáveis pela estrutura resultante da paisagem, que conforme Casseti (1981), “visa à organização de um esboço geomorfológico e estabele uma síntese da compartimentação e seus reflexos na ocupação do solo".

Ross (1996) salienta que a abordagem geomorfológica, nos estudos ambientais, dirige-se a uma geomorfologia que tem as suas bases conceituais nas ciências da Terra, com fortes vínculos nas ciências Humanas, à medida que serve como suporte para o entendimento dos ambientes naturais, onde as sociedades humanas organizam o espaço físico-territorial.

Gregory (1992) destaca ainda que existem diversas tendências no estudo da geomorfologia antrópica, dentre elas, a tendência de mensurar o grau de ação do homem, comparando-se às áreas modificadas e aquelas não-modificadas por ele; a tendência da investigação dos riscos ambientais e a tendência da preocupação com o meio ambiente, com advertências acerca do impacto da atividade humana nos debates a respeito do grau de finitude dos recursos terrestres.

Florenzano (2008) ressalta que os sistemas de 
mapeamento geomorfológicos nem sempre incluem todos os aspectos físicos do relevo, ou dão-lhes a mesma ênfase e destaque de análise. Como exemplo, o pesquisador cita que alguns mapas geomorfológicos que incluem informações geológicas (litologias e materiais inconsolidados ou de formações superficiais). Desta forma, os mapeamentos geomorfológicos apresentam grande diversidade, podendo atender as diferentes necessidades de análise.

Para Ab'Saber (1969), na compreensão da compartimentação geomorfológica, é imprescindível entender o processo evolutivo, considerando a ação diferencial dos processos morfogenéticos: as mudanças climáticas no tempo geológico, os componentes de natureza estrutural, valorizando os mecanismos tectogenéticos e a propriedade das rochas, sem desconsiderar os efeitos da interface em cada estágio de evolução.

Com relação aos mapeamentos geomorfológicos, Ross (1990 e 1992) apresenta uma proposta de compartimentação do relevo em níveis taxonômicos, que se utiliza dos estudos de Ab'Saber (1969), quanto à compartimentação da topografia, análise das formas de relevo e na análise da estrutura superficial da paisagem e dos materiais que dão sustentação às formas.

A compartimentação geomorfológica, adotando sistemática de análise estabelecida por Ross (1990,1992), pode ser encontrada em diversas aplicações de mapeamentos desenvolvidos no Brasil, em que se pode destacar: Ross e Moroz (1996), estabeleceram o Mapa Geomorfológico do Estado de São Paulo na escala 1: 500.000. Os autores, através dos conceitos de morfoestrutura e morfoescultura do relevo, associados aos aspectos morfoclimáticos atuais, apresentam três unidades morfoestruturais Para cada uma das unidades morfoestruturais, eles demarcaram várias unidades morfoesculturais.

Rodrigues e Brito (2000) trabalharam com o mapeamento da bacia hidrográfica do Ribeirão Bom Jardim, nos municípios de Uberaba e Uberlândia, estado de Minas Gerais, onde, através da associação de proposta tradicional de mapeamento com novas técnicas de geoprocessamento, definiram a compartimentação e a separação de segmentos de vertentes, referentes ao quinto nível taxonômico.

Santos et al. (2006) elaboraram o mapeamento geomorfológico do estado do Paraná, para tal, valeram- -se das propostas de Ross (1992) a fim de construir uma sistematização da cartografia geomorfológica regional. A escala adotada foi de 1: 250.000, o que permitiu a utilização dos três primeiros táxons, ou seja, representação cartográfica das Unidades Morfoestruturais, Unidades Morfoesculturais e Sub-unidades Morfoesculturais.

Robaina et al. (2010), por sua vez, utilizam modelo modificado de Ross (1992) para a compartimentação geomorfológica da bacia hidrográfica do Rio Ibicuí, no oeste do estado do Rio Grande do Sul.

Silva e Santos (2010) instituíram a caracterização das unidades geomorfológicas da bacia do Rio Pequeno, município de Antonina, estado do Paraná. Neste trabalho, os autores determinaram os três primeiros níveis taxonômicos em nível da bacia em análise, já o quarto, quinto e sexto níveis taxonômicos foram estabelecidos sobre as unidades da planície fluvial.

O uso dos Sistemas de Informação Geográfica (SIG), nas análises geomorfológicas, proporciona uma maior agilidade na realização de levantamento e processamento das informações, facilitando a tarefa de integração, espacialização dos dados e elaboração dos resultados, como o estudo do relevo por meio da compartimentação geomorfológica.

A partir disso, têm-se como objetivo deste trabalho a compartimentação geomorfológica da bacia do rio Itu (BHRI) que apresenta significativos processos de degradação ambiental, vinculadas a processos de arenização e voçorocamento.

O Rio Itu é afluente da margem direita do Rio Ibicuí e localiza-se no oeste do Rio Grande do Sul, estendendo-se pelos municípios de São Francisco de Assis, Manuel Viana, Itaqui, Unistalda, Maçambará, São Borja e Santiago. Com uma área de 2.809,61 km², a bacia hidrográfica está inserida entre as coordenadas geográficas de $54^{\circ} 52^{\prime} 20^{\prime \prime}$ a $55^{\circ} 53^{\prime} 15^{\prime \prime}$ de longitude oeste, em relação ao meridiano de Greenwich, e de $28^{\circ} 58^{\prime} 00^{\prime \prime}$ a $29^{\circ} 24^{\prime} 40^{\prime \prime}$ de latitude sul, em relação à linha do Equador, como ilustra a Figura 01.

\section{METODOLOGIA}

A concepção teórica metodológica, que norteou o desenvolvimento desta pesquisa, refere-se ao emprego do método de investigação da abordagem sistêmica, tendo como base a proposta de Christofoletti, (1980). 


\section{Localização da bacia hidrográfica do Rio Itu}

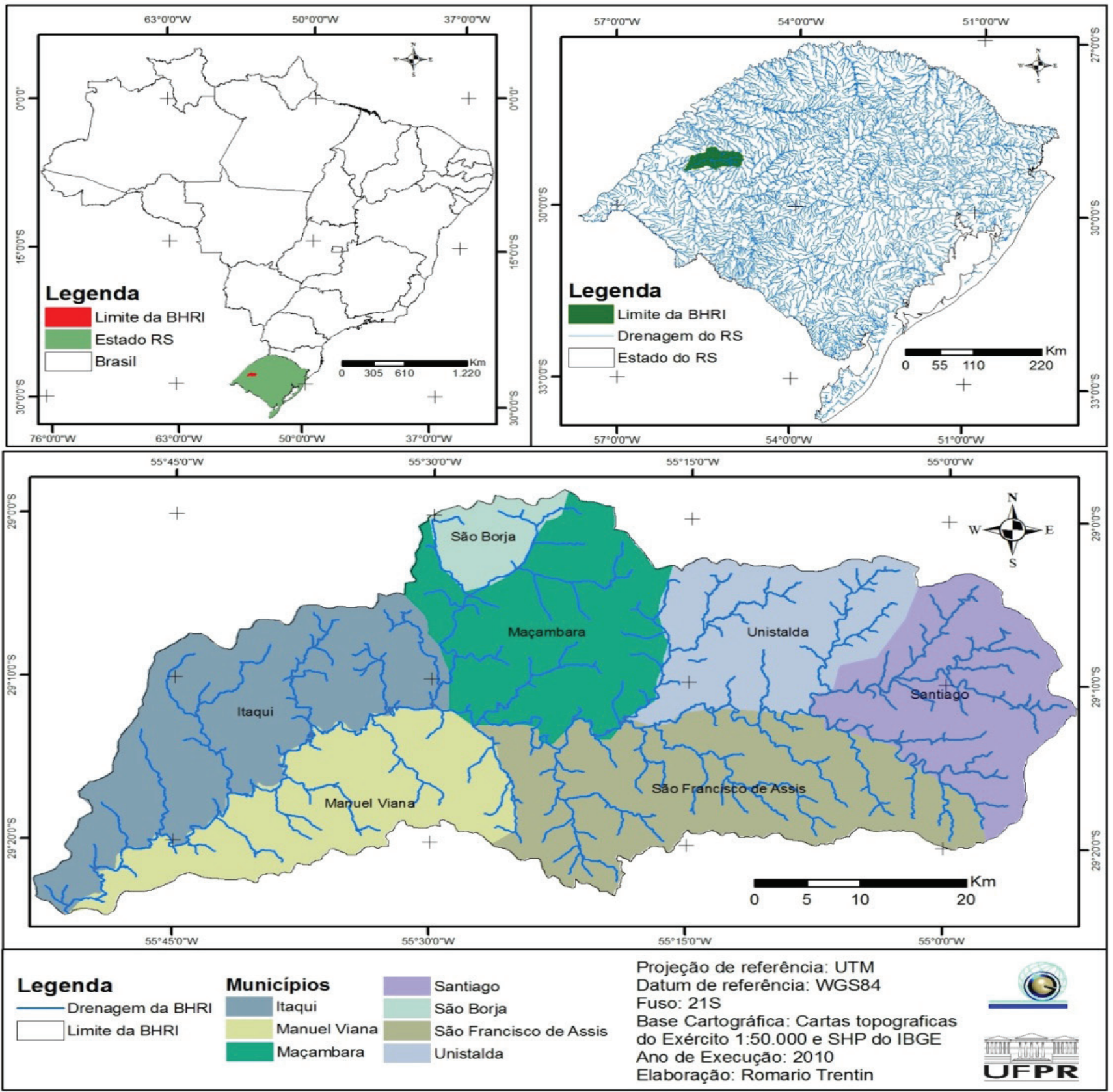

Para o desenvolvimento do trabalho, empregaram-se níveis de abordagem desenvolvidos ao longo da pesquisa para as análises qualitativas e quantitativas, destacando-se sempre que a análise geral do trabalho apresenta uma sistemática de análise qualitativa dos dados; as especificações quantitativas foram utilizadas com o intuito apenas de comparações entre classes e categorias analisadas. 
A análise e a própria escala cartográfica de informação foi construída através de uma metodologia que se aproxima da realidade local e assemelha-se à proposta metodológica de Ross, buscando-se contemplar os seis táxons (níveis), tendo como base as compartimentações gerais já definidas para o Estado.

Os levantamentos dos dados foram realizados através de trabalhos de campo, laboratório e pesquisas secundárias. O levantamento de material e referencial bibliográfico ocorreu durante todo o desenvolvimento da pesquisa, sendo efetivado por meio de consultas, leituras e seleção de bibliografias relacionadas ao tema em estudo, bem como de trabalhos específicos sobre a área e a região de estudo. Pesquisas complementares sobre procedimentos específicos foram realizados ao longo de todo trabalho.

O levantamento de material cartográfico serviu de apoio para a construção dos mapas. A base cartográfica, que se empregou, foi as cartas topográficas do exército, elaboradas pela Diretoria de Serviços Geográfico (DSG/IBGE, 1977), na escala 1:50.000, que, após atualizações por meios de imagens de Satélite LANDSAT 5 e dados de RADAR SRTM/TOPODATA de resolução 30 metros, permitiram a definição do mapa base da área de estudo.

Para o levantamento morfométrico/morfológico do relevo e da rede de drenagem, foram utilizados procedimentos técnicos com o auxílio de SIGs e a análise das cartas topográficas e dos modelos digitais de elevação.

Os dados coletados foram localizados com GPS (Sistema de Posicionamento Global) e, posteriormente, processados servindo de base para a geração dos mapas.

Para o processamento dos dados, foi construído um banco de dados georreferenciado no software SPRING (Sistema de Processamento de Informações Georreferenciadas) em associação com o ArcGis, contendo todas as informações dos levantamentos, contribuindo para a organização e a manipulação dos dados.

A compartimentação geomorfológica foi elaborada sob a base cartográfica de escala 1:50.000.

Dentre os parâmetros físicos analisados para a compartimentação geomorfológica da bacia hidrográfica, destacam-se os atributos da rede de drenagem, atra- vés de análises morfométricas, atributos do relevo com amplitudes, declividades, comprimentos, orientações e curvaturas das vertentes e características litológicas e dos solos da área.

As litologias e solos foram determinados através de trabalhos de campo com traçado de perfis onde eram descritos e coletadas litologias e solos.

Levantamentos fotográficos através de vôos de baixa altitude e fotos oblíquas permitiram identificar as feições superficiais mais importantes, como voçorocas e areais.

\section{DISCUSSÃO DOS RESULTADOS}

A compartimentação geomorfológica da BHRI leva em consideração os processos morfogenéticos e morfodinâmicos do relevo, através da análise e da caracterização dos parâmetros morfológicos e morfométricos da bacia hidrográfica. Para isso, foram definidas as correlações entre os elementos do meio físico, a fim de determinar os limites e as características das formas de relevo (Quadro 01).

\section{Compartimentação do primeiro, segundo e terceiro níveis taxonômicos}

Os três primeiros níveis taxonômicos foram identificados e caracterizados levando-se em consideração a bacia hidrográfica do Rio Ibicui, da qual o Rio Itu é afluente, seguindo proposta apresentada por Robaina, et al. (2010).

O $1^{\circ}$ nível taxonômico apresenta os Domínios Morfoestruturais, nos quais a bacia hidrográfica do Rio Itu encontra-se inserida que são: a Depressão Periférica do Rio Grande do Sul e o Planalto Serra Geral.

A Depressão Periférica do Rio Grande do Sul forma uma faixa E-W no Estado e representa uma área deprimida, formada pelo contato entre os terrenos de rochas sedimentares e as rochas cristalinas mais coesas. O substrato é formado por uma sequência de coberturas sedimentares da Bacia do Paraná e depósitos recentes dos rios.

A Depressão do Ibicuí marca o $\mathbf{2}^{\mathbf{0}}$ nível taxonômico constituindo a porção oeste da Depressão 
Quadro 01 - Distribuição dos níveis de compartimentação geomorfológica da BHRI

\begin{tabular}{|c|c|c|c|c|c|}
\hline $1^{\circ}$ Nível & $2^{\circ}$ Nível & $3^{\circ}$ Nível & $4^{0}$ Nível & $5^{\circ}$ Nível & $6^{0}$ Nível \\
\hline \multirow{4}{*}{$\begin{array}{c}\text { Depressão } \\
\text { Periférica do } \\
\text { RS }\end{array}$} & \multirow{4}{*}{$\begin{array}{c}\text { Depressão } \\
\text { do Rio Ibicui }\end{array}$} & \multirow{3}{*}{$\begin{array}{l}\text { Patamares } \\
\text { residuais em } \\
\text { arenito }\end{array}$} & $\begin{array}{l}\text { Colinas de } \\
\text { arenito }\end{array}$ & $\begin{array}{c}\text { Rt-Dt; Rt-Ct e } \\
\mathrm{Cc}-\mathrm{Ct}\end{array}$ & $\begin{array}{c}\text { Areais; Ravinas e } \\
\text { voçorocas }\end{array}$ \\
\hline & & & $\begin{array}{l}\text { Morrotes de } \\
\text { Arenito }\end{array}$ & $\begin{array}{c}\text { Rt-Dt; Rt-Ct e } \\
\mathrm{Cc}-\mathrm{Ct}\end{array}$ & \multirow{2}{*}{$\begin{array}{l}\text { Depósitos de } \\
\text { colúvio e Areais }\end{array}$} \\
\hline & & & $\begin{array}{l}\text { Cornijas de } \\
\text { arenito }\end{array}$ & $\mathrm{Cx}-\mathrm{Dt} ; \mathrm{Cx}-\mathrm{Ct}$ & \\
\hline & & $\begin{array}{l}\text { Modelado de } \\
\text { áreas planas } \\
\text { aluviais }\end{array}$ & $\begin{array}{c}\text { Rampa alúvio } \\
\text { colúvio }\end{array}$ & Rt-Dt; Rt-Ct & $\begin{array}{l}\text { Depósitos dos } \\
\text { arroios e rios }\end{array}$ \\
\hline \multirow{4}{*}{$\begin{array}{c}\text { Planalto Serra } \\
\text { Geral }\end{array}$} & \multirow{2}{*}{$\begin{array}{l}\text { Planalto das } \\
\text { Missões }\end{array}$} & $\begin{array}{c}\text { Modelado de } \\
\text { patamares das } \\
\text { Missões }\end{array}$ & $\begin{array}{c}\text { Colinas } \\
\text { vulcânicas de } \\
\text { topo plano }\end{array}$ & $\begin{array}{c}\text { Rt-Dt; Rt-Ct e } \\
\text { Cx-Dt }\end{array}$ & $\begin{array}{l}\text { Afloramentos de } \\
\text { rochas e depósitos } \\
\text { de colúvio }\end{array}$ \\
\hline & & $\begin{array}{c}\text { Modelado de } \\
\text { Rebordo do } \\
\text { Planalto } \\
\end{array}$ & $\begin{array}{l}\text { Relevo } \\
\text { escarpado }\end{array}$ & $\mathrm{Cc}-\mathrm{Ct} ; \mathrm{Cx}-\mathrm{Dt}$ & \multirow{2}{*}{$\begin{array}{l}\text { Escarpas e } \\
\text { depósitos de } \\
\text { colúvio }\end{array}$} \\
\hline & \multirow{2}{*}{$\begin{array}{l}\text { Planalto da } \\
\text { Campanha }\end{array}$} & \multirow{2}{*}{$\begin{array}{l}\text { Modelado de } \\
\text { baixo platô da } \\
\text { Campanha }\end{array}$} & $\begin{array}{l}\text { Morrotes de } \\
\text { rocha } \\
\text { vulcânica } \\
\end{array}$ & $\begin{array}{l}\text { Rt-Dt; } \mathrm{Rt}-\mathrm{Ct} \text { e } \\
\mathrm{Cc}-\mathrm{Ct}\end{array}$ & \\
\hline & & & $\begin{array}{l}\text { Colinas de } \\
\text { rocha } \\
\text { vulcânica }\end{array}$ & Rt-Dt; Rt-Ct & $\begin{array}{l}\text { Ravinas e } \\
\text { voçorocas }\end{array}$ \\
\hline
\end{tabular}

$\mathrm{Cc}=$ Côncavo $\mathrm{Cx}=$ Convexo; $\mathrm{Rt}=$ Retilíneo; $\mathrm{Ct}=$ Convergente Dt=Divergente; $\mathrm{Pn}=\mathrm{Planar}$

Org. dos autores.

Periférica do RS, com processos geomorfológicos controlados pela drenagem do Rio Ibicuí e seus afluentes.

O Planalto Serra Geral, apresenta a sua origem ligada ao vulcanismo que cobriu os sedimentos da Bacia do Paraná, na região, aparece de forma fragmentada em duas áreas, uma a nordeste e outra a oeste, determinando o $2^{\circ}$ nível taxonômico que são: o Planalto das Missões e o Planalto da Campanha.

A nordeste, o Planalto das Missões compreende a área desde as nascentes do Ibicuí-Mirim até as nascentes do Rio Itu. Nesta parte, ocorrem as áreas de maiores altitudes da bacia (ao redor de 400 metros) que correspondem aos topos regionais e pertencem aos restos de uma superfície de aplanamento.

O Planalto da Campanha apresenta uma significativa relação com o que Chebataroff (1954, apud MÜLLER FILHO, 1970) define como Cuesta de Ha- edo. O planalto está representado por um relevo ondulado, com altitudes inferiores a 300 metros, a partir do baixo curso do Rio Itu e da bacia do Rio Ibirapuitã, a norte e sul do Ibicuí, respectivamente, decaindo de forma gradativa em direção a calha do Rio Uruguai.

Esse compartimento apresenta menor número de derrames, quando comparado com a porção nordeste da bacia hidrográfica do Rio Ibicuí, tendo como consequência as diferenças de altitudes. A pouca espessura dos derrames, nesta porção, possibilita o afloramento de arenitos em algumas áreas, com o desgaste das camadas superiores, observados também na base de morros testemunhos.

No $3^{\mathbf{0}}$ nível taxonômico encontram-se apresentadas as unidades geomorfológicas correspondentes à bacia do Rio Itu que são: Patamares Residuais em Arenitos, Modelado de Áreas Planas Aluviais, Mode- 
lado de Patamares das Missões, Modelado de Rebordo do Planalto e Modelado de Baixo Platô da Campanha.

Os Patamares Residuais em Arenitos compõem formas de relevo do tipo colinas, associadas a morrotes isolados de arenitos. As colinas formam um relevo ondulado, integradas associadas com vertentes alongadas de topo suavemente ondulado, com altitudes que variam entre 120 a 200 metros. As formas residuais ocorrem por maior resistência aos processos erosivos devido à existência de arenitos com camadas cimentadas por óxido de ferro e, por vezes, sílica. A resistência que se estabelece, a partir de camadas, gera morrotes de topo plano e vertentes íngremes, regionalmente denominados cerros. Também é comum o registro de porções resistentes, na meia vertente, formando degrau de rocha exposta.

O Modelado de Áreas Planas Aluviais constitui formas de relevo aplainadas, situado em altitudes entre 80 e 100 metros. Forma um relevo de agradação caracterizado por depósitos sedimentares de canal, planície de inundação e terraços dos rios. Uma importante característica do leito menor destes rios é o desenvolvimento de bancos de areia que indicam a ocorrência de raios mais reduzidos para o leito de estiagem. A baixa declividade desta unidade forma áreas planas sujeitas a inundações periódicas, favorecendo os processos de acumulação e deposição de sedimentos. Os solos são predominantemente do tipo Planossolos arenosos e Gleissolos.

Os Modelados de Patamares das Missões correspondem à porção de maiores altitudes, situadas entre 300 e 500 metros, junto às nascentes do Arroio Ibicuí-Mirim e Guassupi a leste, do Rio Toropi e Rio Jaguari a norte, até o alto do Rio Itu. Esta unidade apresenta, como principais características, um relevo suavemente ondulado no alto curso da bacia hidrográfica, com formas de colinas que passam para um relevo ondulado com uma associação de morros e morrotes em direção ao rebordo. Os cursos d'água apresentam um padrão retangular controlado pelas estruturas geológicas.

O Modelado do Rebordo do Planalto corresponde às escarpas abruptas associadas a formas de morros e morrotes, localizados na transição entre o Planalto Serra Geral e a Depressão Periférica. Sua configuração acidentada testemunha a atual fase de evolução do Planalto. As altitudes estão situadas entre 100 e
400 metros de altitude, enquanto as declividades estão entre 15 e $30 \%$. O substrato geológico é constituído por rocha vulcânica, com intertraps de rochas areníticas coesas.

O Modelado do Baixo Platô da Campanha ocorre a partir do baixo curso do Rio Ibirapuitã e do baixo curso do Rio Itu, a sul e a norte do Rio Ibicuí, respectivamente, em direção ao Rio Uruguai. Correspondem à área de $8.206 \mathrm{~km}^{2}$, cerca de $26,2 \%$ da área total da bacia hidrográfica do Rio Ibicuí.

As altitudes são, em geral, inferiores a 100 metros e as declividades inferiores a $5 \%$. As formas de relevo predominantes são colinas e rampas. O substrato é formado por uma sequência de dois a três derrames de rochas vulcânicas com intercalações de arenitos. Nos locais de contato, formam degraus, com acúmulo de água.

\section{Compartimentação do quarto, quinto e sexto níveis taxonômicos}

O quarto, quinto e sexto níveis taxonômicos são analisados e caracterizados, tendo como limite físico a área drenada pela BHRI. Na Figura 02, são apresentadas as formas de relevo identificadas na bacia hidrográfica.

No quarto nível taxonômico, são definidas oito formas de relevo: colinas de arenito, morrotes de arenito, cornijas de arenito, rampa alúvio colúvio, colinas vulcânicas de topo plano, relevo escarpado, morrotes de rocha vulcânica e colinas de rocha vulcânica, que são apresentadas no Quadro 02 e passam a ser descritas a seguir. 
Quadro 02 - Principais características determinadas na bacia hidrográfica do Rio Itu

\begin{tabular}{|c|c|c|c|c|c|}
\hline $4^{\circ}$ Nível & $\begin{array}{c}\text { Decli- } \\
\text { vidade }\end{array}$ & Altitudes & Substrato & Solos & $\begin{array}{l}\text { \% da } \\
\text { área }\end{array}$ \\
\hline $\begin{array}{l}\text { Colinas de } \\
\text { arenito }\end{array}$ & $\begin{array}{l}\text { Inferior a } \\
15 \%\end{array}$ & $\begin{array}{l}120 \text { a } 200 \\
\text { metros }\end{array}$ & $\begin{array}{l}\text { Arenito fluvial } \\
\text { (Formação Guará) }\end{array}$ & $\begin{array}{l}\text { Muito arenosos (Latossolos e } \\
\text { Neossolos predominantemente) } \\
\text { Planossolos junto às drenagens. }\end{array}$ & 29,78 \\
\hline $\begin{array}{l}\text { Morrotes de } \\
\text { arenito }\end{array}$ & $\begin{array}{l}\text { Superior } \\
\text { a } 15 \%\end{array}$ & $\begin{array}{l}120 \text { a } 200 \\
\text { metros }\end{array}$ & $\begin{array}{l}\text { Arenito fluvial } \\
\text { (Formação Guará) }\end{array}$ & $\begin{array}{l}\text { Profundos e arenosos e, junto aos } \\
\text { cerros e morrotes, afloramentos } \\
\text { de rocha. }\end{array}$ & 4,92 \\
\hline $\begin{array}{l}\text { Cornijas de } \\
\text { arenito }\end{array}$ & $\begin{array}{l}\text { Superior } \\
\text { a } 15 \%\end{array}$ & $\begin{array}{l}120 \text { a } 200 \\
\text { metros }\end{array}$ & $\begin{array}{l}\text { Predominam os } \\
\text { arenitos fluviais } \\
\text { (Formação Guará) }\end{array}$ & $\begin{array}{l}\text { Predominam os afloramentos de } \\
\text { rochas. }\end{array}$ & \\
\hline $\begin{array}{l}\text { Rampas de } \\
\text { alúvio colúvio }\end{array}$ & $\begin{array}{l}\text { Inferior a } \\
2 \%\end{array}$ & $\begin{array}{l}\text { Inferior a } \\
80 \text { metros }\end{array}$ & $\begin{array}{l}\text { Depósitos recentes } \\
\text { do Rio Itu e Ibicuí }\end{array}$ & $\begin{array}{l}\text { Solos hidromórficos, } \\
\text { predominando os Planossolos. }\end{array}$ & 3,11 \\
\hline $\begin{array}{c}\text { Colinas } \\
\text { vulcânicas de } \\
\text { topo plano }\end{array}$ & 5 a $15 \%$ & $\begin{array}{l}\text { Inferiores } \\
\text { a } 20 \\
\text { metros }\end{array}$ & Rochas vulcânicas & $\begin{array}{l}\text { Predominam associações de } \\
\text { Neossolos e Cambissolos, porém, } \\
\text { dependendo da posição do relevo } \\
\text { e da porção do derrame, há } \\
\text { porções de solos mais } \\
\text { desenvolvidas. }\end{array}$ & 10,11 \\
\hline $\begin{array}{l}\text { Relevo } \\
\text { escarpado }\end{array}$ & $\begin{array}{l}\text { Superior } \\
\text { a } 15 \%\end{array}$ & $\begin{array}{l}200 \text { a } 400 \\
\text { metros }\end{array}$ & $\begin{array}{l}\text { Rochas vulcânicas } \\
\text { (Rebordo do } \\
\text { planalto) }\end{array}$ & $\begin{array}{l}\text { Solos rasos e bastante pedregosos, } \\
\text { com afloramento de blocos de } \\
\text { rochas associados ao solo. }\end{array}$ & 19,7 \\
\hline $\begin{array}{l}\text { Morrotes de } \\
\text { rocha } \\
\text { vulcânica }\end{array}$ & $\begin{array}{l}\text { Superior } \\
\text { a } 15 \%\end{array}$ & $\begin{array}{l}\text { Inferiores } \\
\text { a } 200 \\
\text { metros }\end{array}$ & Rochas vulcânicas & $\begin{array}{l}\text { Solos rasos, (associação de } \\
\text { Neossolos e Cambissolos), } \\
\text { podendo ocorrer solos mais } \\
\text { profundos nas porções de base } \\
\text { dos cerros, nas áreas de contatos } \\
\text { litológicos. }\end{array}$ & 3,68 \\
\hline $\begin{array}{l}\text { Colinas de } \\
\text { rocha } \\
\text { vulcânicas }\end{array}$ & 5 a $15 \%$ & $\begin{array}{l}80 \text { a } 200 \\
\text { metros }\end{array}$ & Rochas vulcânicas & \begin{tabular}{llr} 
Solos bem & \multicolumn{2}{c}{ desenvolvidos } \\
(Nitossolos e Argissolos). Nas \\
áreas planas, próximas a rede de \\
drenagem, registra-se & o \\
desenvolvimento Plintossolos & e \\
Luvissolos. & & \\
\end{tabular} & 26,60 \\
\hline
\end{tabular}

Org. dos autores. 
Figura 02 - Mapa geomorfológico da bacia hidrográfica do Rio Itu

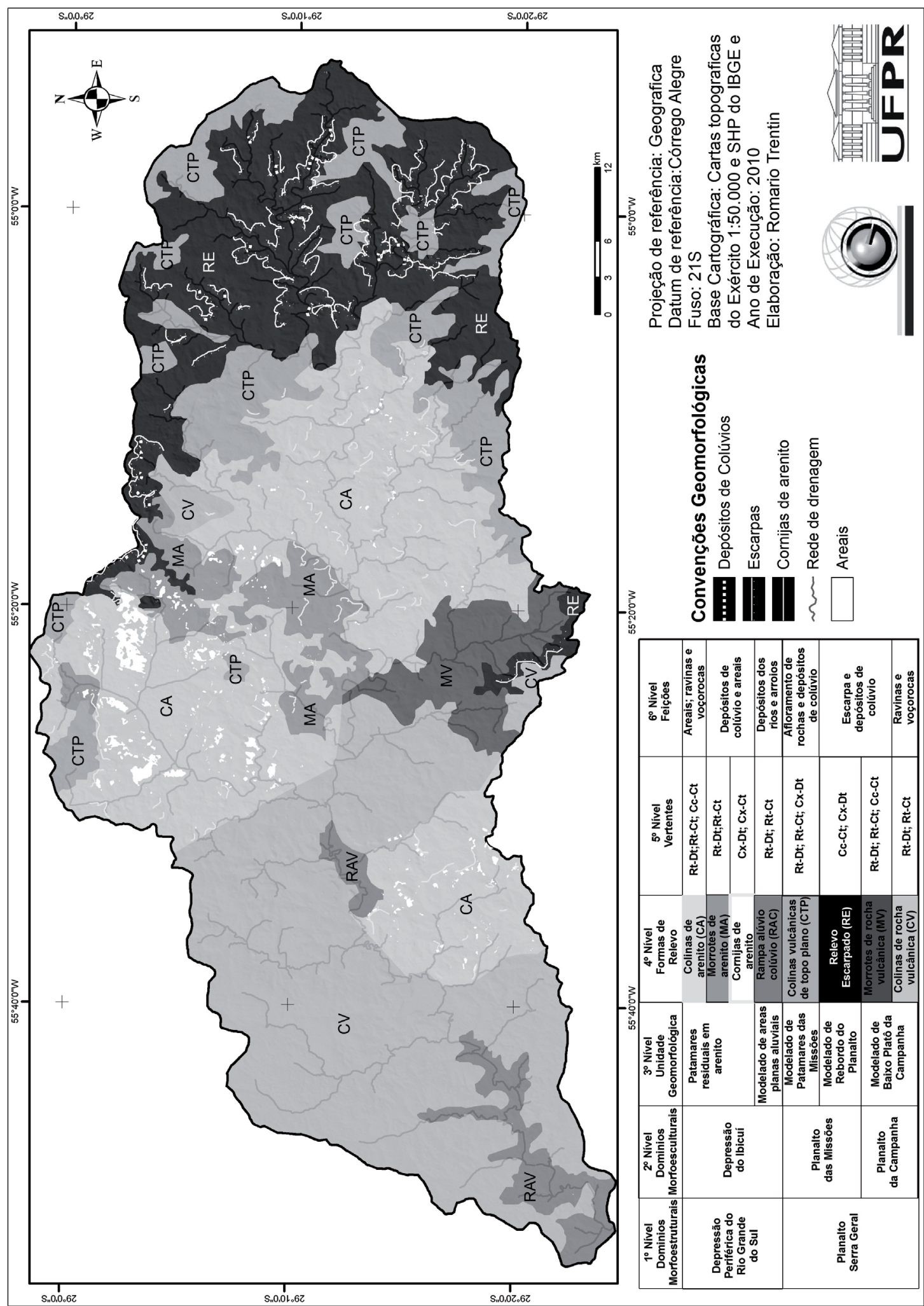

Soc. \& Nat., Uberlândia, ano 24 n. 1, 127-142, jan/abr. 2012 
- Colinas de arenito: As colinas de arenito são caracterizadas por áreas planas a suavemente onduladas com pequenas amplitudes e sua ocorrência concentra-se no médio e no baixo curso da BHRI. Esta unidade é a que ocupa a maior área na BHRI (Figura 03).

Figura 03 - Processos de voçorocamento e arenização em colinas de arenito

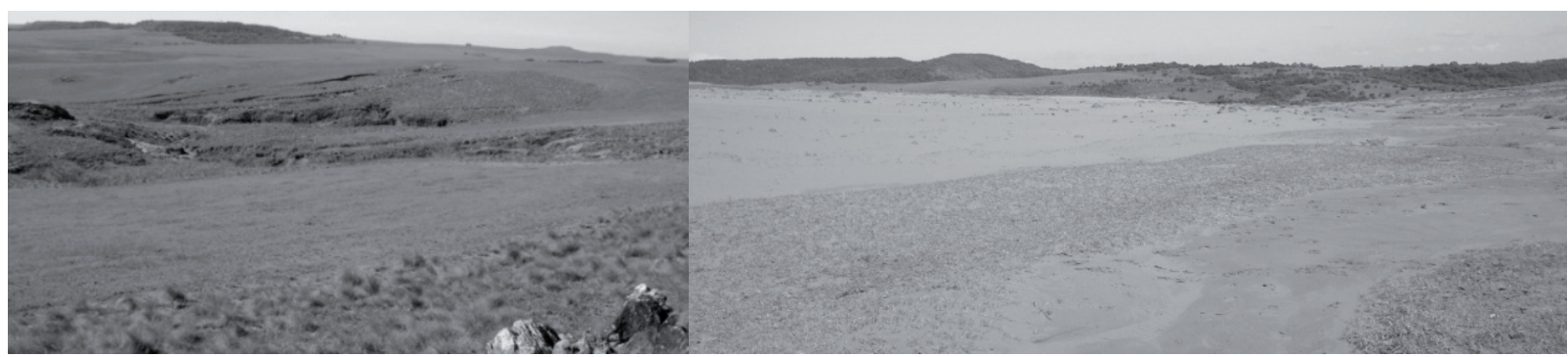

Foto dos autores.

- Morrotes de arenito: Os morrotes de arenito são caracterizados pelo relevo ondulado a fortemente ondulado, de morros e morrotes, regionalmente denominados de cerros, de acordo com Figura 04. Esta unidade ocupa a porção central da bacia, com altitudes que variam de 120 a 200 metros.

Figura 04 - Morrote de arenito com afloramentos de blocos de rochas

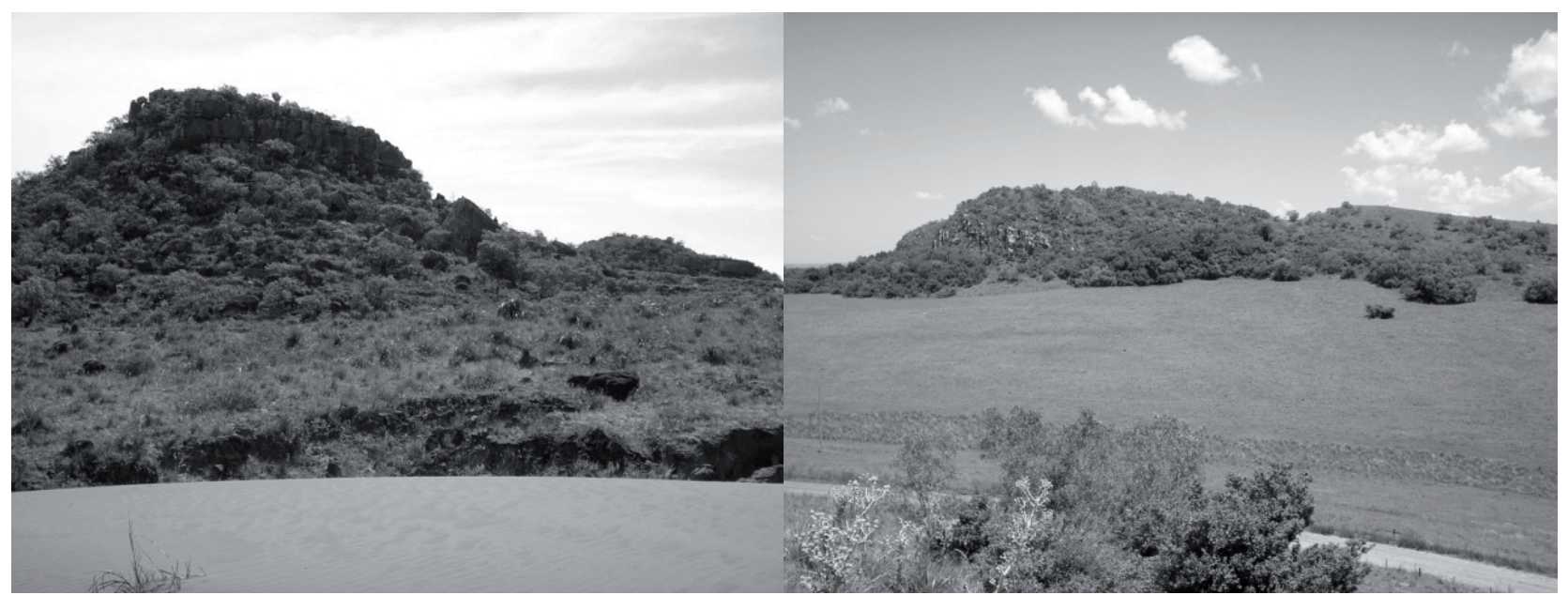

Foto dos autores.

- Cornijas de arenito: As cornijas de arenito verificam-se em associação às colinas de arenitos e aos morrotes de arenito, na porção do médio curso predominantemente.

Na bacia hidrográfica do Rio Itu, as cornijas são identificadas quando a cimentação de óxido de ferro preenche os espaços dos poros, atribuindo maior resistência aos arenitos fluviais. A maior resistência dos arenitos também pode acontecer junto às linhas de falhas, em que estes arenitos aparecem silicificados ou com maior resistência aos processos de dinâmica superficial, que os torna salientes no relevo.

$\mathrm{Na}$ maioria das vezes, as cornijas aparecem associadas com presença de vegetação arbórea reco- 
brindo às vertentes. Na BHRI, as cornijas possuem ainda uma característica bastante comum do Oeste do Rio Grande do Sul, compreendida pela associação a uma forma de relevo que possui apenas uma porção de suas vertentes escarpadas, enquanto a outra porção, com vertentes planas a levemente onduladas, como observa-se na Figura 05, o que as diferencia dos mor- rotes de arenito.

$\mathrm{Na}$ referida figura, verificar-se também que a porção escarpada do relevo, associada às Cornijas, possui vegetação arbórea e o topo geralmente plano, havendo continuidade uniforme na vertente oposta, com a ocorrência de campos ou lavouras de cultivos.

Figura 05 - Visualização da cornija em fotografia aérea de baixa altitude

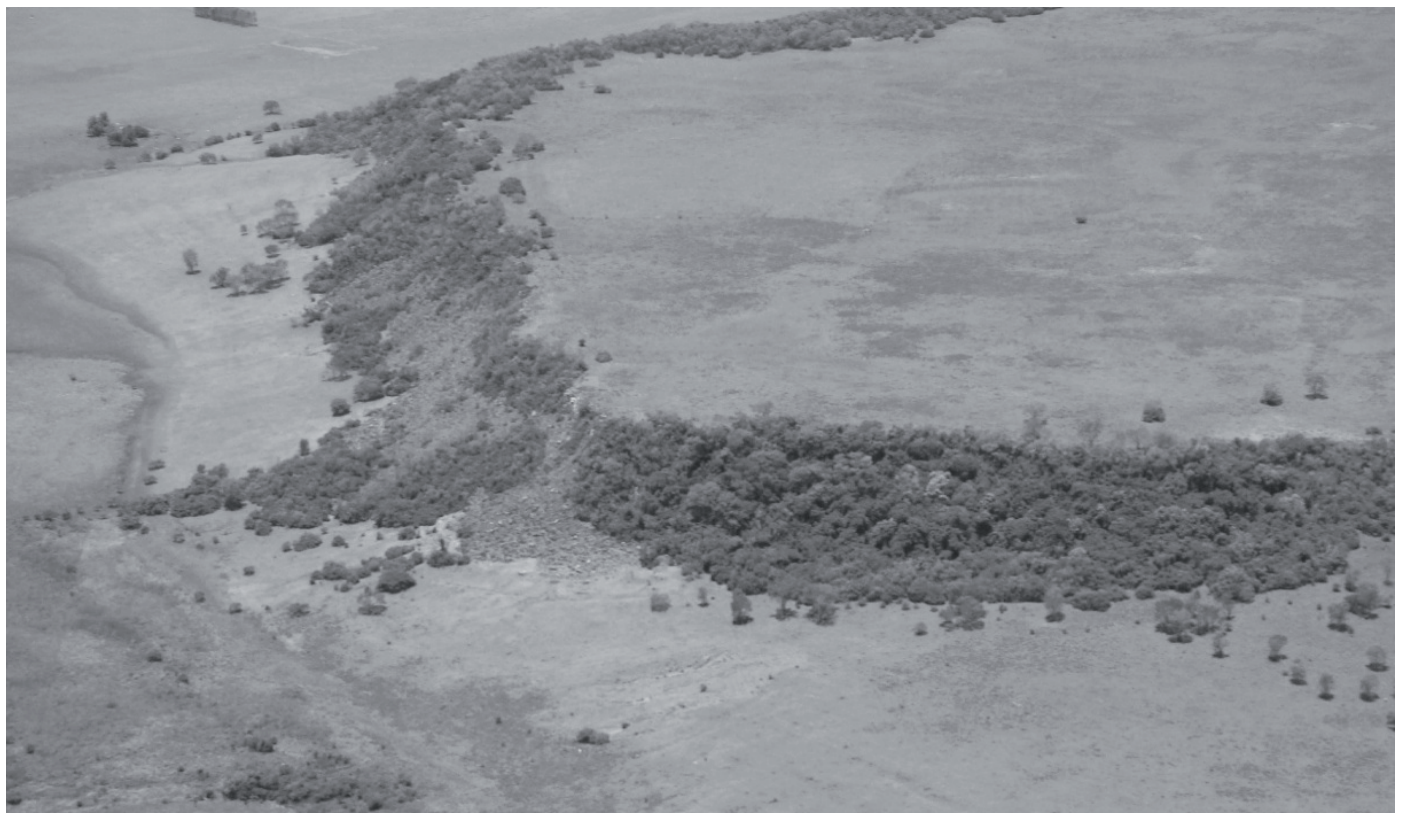

Foto dos autores.

- Rampas de alúvio colúvio: As rampas de alúvio colúvio são caracterizadas pela sua topografia plana, com declividades $<2 \%$ e as altitudes inferiores a 80 metros. Esta unidade localiza-se no baixo curso da bacia hidrográfica, nas áreas próximas à rede de drenagem.
- Colinas vulcânicas de topo plano: As colinas vulcânicas de topo plano são caracterizadas por um relevo plano a levemente ondulado. Ocorrem, principalmente, no alto curso da bacia hidrográfica, observada na Figura 06. O substrato sobre o qual esta unidade encontra-se é formado por rochas vulcânicas do topo de planalto.

Figura 06 - Topografia levemente ondulada, característico das colinas vulcânicas de topo plano

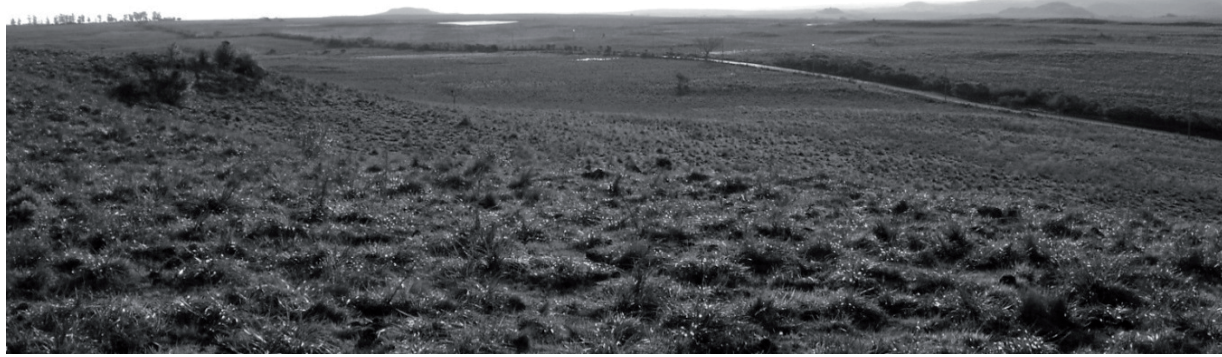

Foto dos autores. 
- Relevo escarpado: O relevo escarpado caracteriza-se por ser fortemente ondulado, com presença de vertentes escarpadas, conforme ilustra a Figura 07 , localiza-se, principalmente, no alto curso da bacia hidrográfica. O substrato geológico encontrado, nesta área, é constituído de rocha vulcânica do rebordo do planalto.

Figura 07 - Fotos mostrando, ao fundo, relevo fortemente ondulado da área do rebordo do planalto

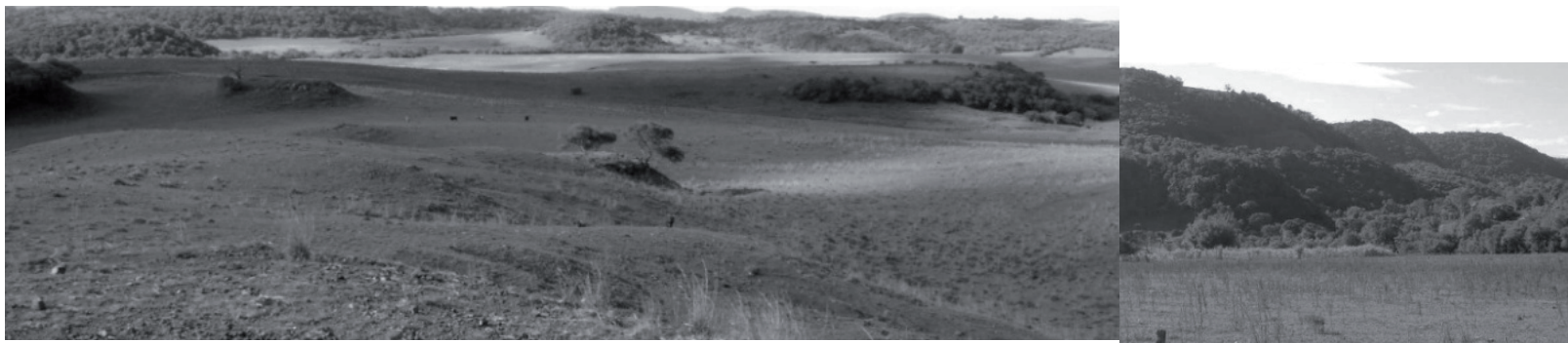

Foto dos autores.

- Morrotes de rocha vulcânica: Os morrotes de rocha vulcânica identificam-se pelo relevo on- dulado a fortemente ondulado, de cerros e morrotes, visualizados na Figura 08.

Figura 08 - Morrotes de rocha vulcânica

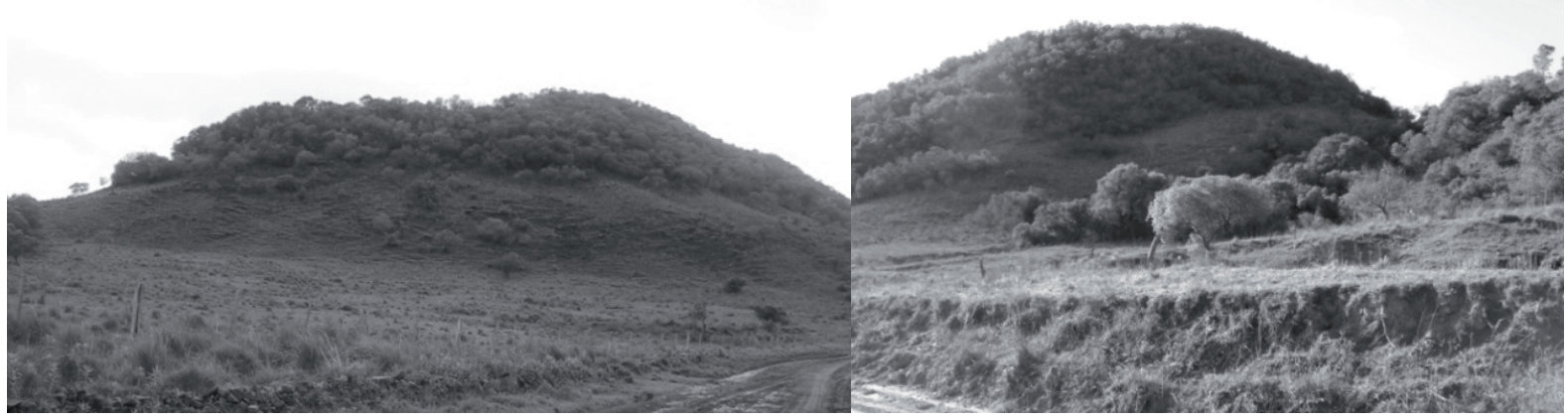

Foto dos autores.

- Colinas de rocha vulcânicas: As colinas de rochas vulcânicas, identificadas na Figura 09, são caracterizadas pelas áreas planas a suavemente on- duladas, com substrato geológico de rochas vulcânicas. Esta unidade ocorre, principalmente, no baixo curso da bacia hidrográfica.

Figura 09 - Lavouras nas áreas suavemente onduladas das colinas de rocha vulcânica

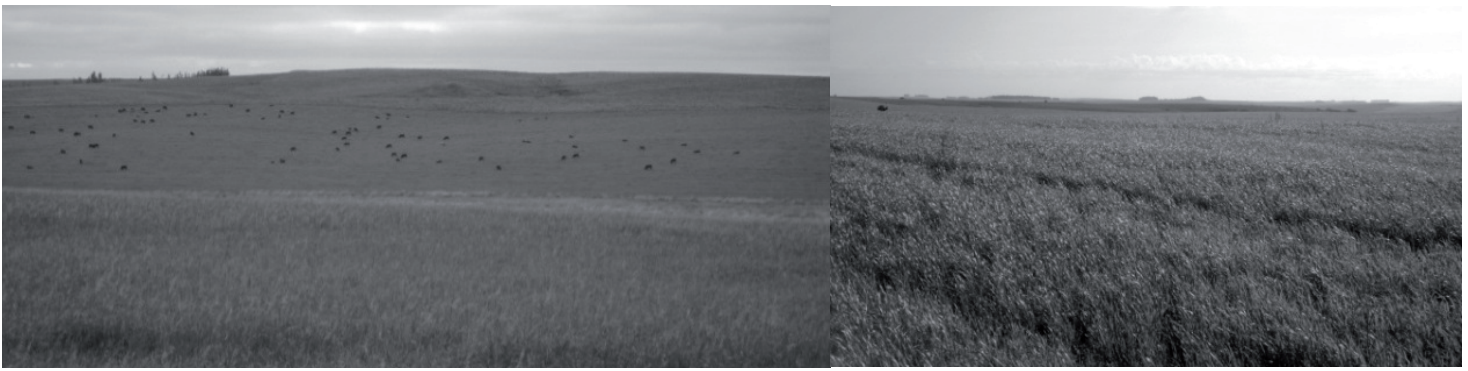

Foto dos autores.

Soc. \& Nat., Uberlândia, ano 24 n. 1, 127-142, jan/abr. 2012 
O quinto nível é definido pelos padrões de vertentes e topos que ocorrem em cada modelado de relevo definido, conforme Quadro 03.

Como se pode observar, a bacia hidrográfica do Rio Itu apresenta um relevo característico, com predomínio de segmentos de vertentes retilíneos divergentes, ocorrendo ainda, com grande frequência, os segmentos de vertentes retilíneas convergentes, côncavas convergentes, junto ao fundo de vale, e convexas convergentes, junto às porções superiores das vertentes.

O sexto nível taxonômico é assinalado pelas feições superficiais que se verificaram na área de es- tudo.

Nas colinas de arenito, são comuns a ocorrência das feições superficiais de areais, ravinas e voçorocas. Por ser uma forma de relevo associada aos arenitos muito friáveis, e os solos serem muito arenosos, o desenvolvimento da vegetação, principalmente as gramíneas associadas aos campos, é muito ralo o que torna estas áreas bastante susceptíveis aos processos de dinâmica superficiais.

Quadro 03 - Porcentagem de ocorrência das curvaturas das vertentes em cada unidade geomorfológica

\begin{tabular}{|l|r|r|r|r|r|r|r|r|}
\hline Classe & $\begin{array}{c}\text { Colinas } \\
\text { de } \\
\text { Arenito }\end{array}$ & $\begin{array}{c}\text { Colinas } \\
\text { de rocha } \\
\text { vulcânica }\end{array}$ & $\begin{array}{c}\text { Colinas } \\
\text { vulcânicas } \\
\text { de topo } \\
\text { plano }\end{array}$ & $\begin{array}{c}\text { Morrotes } \\
\text { de Arenito }\end{array}$ & $\begin{array}{c}\text { Morrotes } \\
\text { de rocha } \\
\text { vulcânica }\end{array}$ & $\begin{array}{c}\text { Rampa } \\
\text { Alúvio } \\
\text { Colúvio }\end{array}$ & $\begin{array}{c}\text { Relevo } \\
\text { escarpado }\end{array}$ & $\begin{array}{c}\text { Cornijas } \\
\text { de } \\
\text { arenito }\end{array}$ \\
\hline Cc_Ct & 13,64 & 12,57 & 13,26 & 16,09 & 17,47 & 8,86 & 21,38 & 11,32 \\
\hline Rt_Ct & 21,39 & 23,54 & 21,53 & 17,64 & 17,95 & 31,35 & 14,22 & 37,90 \\
\hline Cx_Ct & 1,73 & 1,49 & 3,00 & 2,23 & 2,33 & 0,92 & 4,08 & 20,00 \\
\hline Cc_Pn & 4,49 & 3,45 & 3,40 & 5,71 & 4,79 & 2,47 & 6,62 & 6,43 \\
\hline Rt_Pn & 12,43 & 12,36 & 11,75 & 10,25 & 10,30 & 12,42 & 6,89 & 12,56 \\
\hline Cx_Pn & 2,28 & 1,79 & 3,23 & 3,09 & 2,54 & 0,79 & 4,10 & 6,98 \\
\hline Cc_Dt & 4,91 & 3,92 & 3,79 & 6,32 & 5,73 & 3,79 & 8,50 & 1,29 \\
\hline Rt_Dt & 27,72 & 30,17 & 26,19 & 24,54 & 24,21 & 32,83 & 14,34 & 2,33 \\
\hline Cx_Dt & 11,41 & 10,71 & 13,84 & 14,13 & 14,68 & 6,58 & 19,87 & 1,19 \\
\hline Cc=Côncavo; Rt= Retilíneo; Cx= Convexo; Ct= Convergente; Pn=Planar; Dt= Divergente \\
\hline
\end{tabular}

Org. dos autores.

O registro das feições superficiais nas colinas de arenito, ilustrada na Figura 10, pode ser caracteri- zada pelo solo com vegetação de gramínea muito rala, favorecendo o desenvolvimento dos processos de ravinas e voçorocas e, além disso, areiais.

Figura 10 - Areais e voçorocas caracterizando as feições superficiais das colinas de arenito

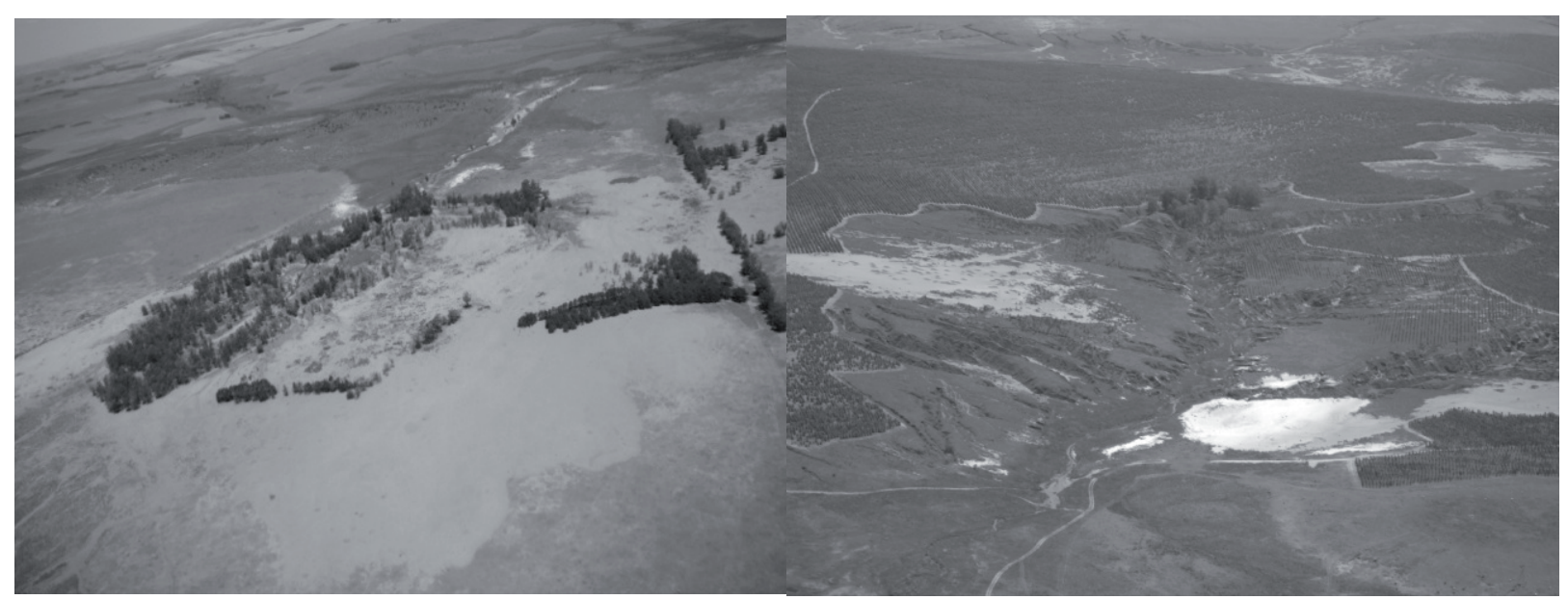

Foto dos autores. 
Nas vertentes dos morrotes e cornijas de arenito, além dos areais e voçorocas são comuns as feições superficiais definidas como depósitos de colúvio associados à base das vertentes. Nestas áreas, nota-se que, junto às porções mais íngremes das vertentes, geralmente, há a presença de vegetação arbórea.

Outra característica encontrada, especificamente nas vertentes dos morrotes e cornijas de arenito, é a existência de cachoeiras, devido à resistência da rocha, os cursos de água não conseguem aprofundar-se e formam cachoeiras ao transpor estes degraus do relevo. Também é bastante comum, principalmente nas cornijas de arenito, estas áreas servirem como regiões de refúgios de espécies xerófitas.

Nas áreas próximas aos cursos de água, que formam as rampas de alúvio colúvio, são constatados os depósitos de sedimentos quaternários.

Nas colinas vulcânicas de topos planos, relevo escarpado, morrotes de rocha vulcânica e colinas de rocha vulcânica, tem-se o afloramento de rochas vulcânicas em blocos e pequenos lajeados nas formas de relevo das colinas vulcânicas de topo plano.

No relevo escarpado e nos morrotes de rocha vulcânica, é comum a ocorrência de depósitos de colúvio na base das vertentes, formados por blocos de rochas envoltos em solo oriundo das porções superiores das vertentes, além da presença de escarpas.

Cabe destacar ainda os afloramentos de concreções de ferro na forma de carapaças, que, em geral, aparecem associados aos arenitos fluviais ou porções próximas a contatos litológicos. Por vezes, estes afloramentos formam pequenos degraus nas colinas como

Figura 11 - Afloramento de concreções de ferro na forma de carapaças formando pequeno degrau na meia encosta

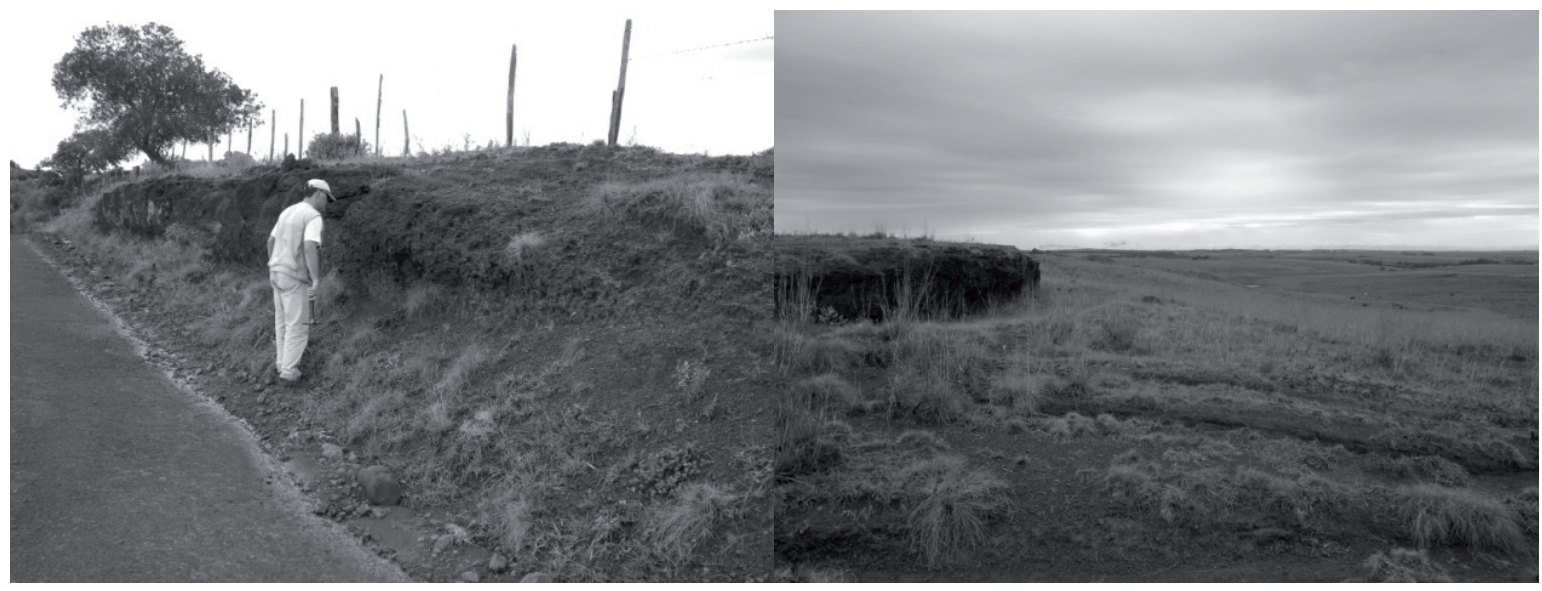

Foto dos autores.

pode ser observado na Figura 11.

\section{CONSIDERAÇÕES FINAIS}

A bacia hidrográfica do Rio Itu apresenta-se em um contexto junto ao estado do Rio Grande do Sul, no qual ocorrem significativos processos de degradação ambiental relacionadas aos processos de arenização e voçorocamento. A compartimentação geomorfológica, aqui, apresentada procurou definir, de maneira geral, as formas e as unidades de relevo da referida bacia hidrográfica, identificando as principais feições encontradas nestas áreas.

Para a bacia hidrográfica, foram definidas oito formas de relevo sendo elas: as colinas de arenito, os morrotes de arenito, as cornijas de arenito, as rampas de alúvio colúvio, o relevo escarpado, os morrotes de rocha vulcânica e as colinas de rocha vulcânicas, sendo identificadas as feições do tipo areais e voçorocas como as principais feições superficiais da bacia hidrográfica, estando associadas às formas de relevo sobre o substrato arenito. Também são identificados depósitos de colúvios, afloramentos de rochas e concreções ferro que caracterizam as feições encontradas na área.

O mapa geomorfológico representa um dos produtos muito importante na análise do meio físico, que pode ainda ser utilizado como produto base para 
compartimentação geoambiental, quando combinado aos processos de uso e ocupação da terra e da cobertura vegetal.

O refinamento das informações geomorfológicas, quanto à definição dos níveis taxonômicos com maior detalhamento de processos identificados no mapeamento geomorfológico, permite melhor subsídio na identificação de potencialidades e fragilidades da área.

No que diz respeito à relevância do trabalho, entende-se que ele serve como base para estudos de maiores detalhes e sugere-se aproximar a discussão para a aplicação do planejamento e ordenamento territorial, uma vez que as ocupações nem sempre são precedidas de estudos que considerem as restrições dos recursos naturais.

\section{REFERÊNCIAS}

AB'SABER, A. N. Um conceito de geomorfologia a serviço das pesquisas sobre o quartenário. Geomorfologia, São Paulo: USP, n.19, p,1-23, 1969.

CASSETI, V. Estrutura e Gênese da Compartimentação da Paisagem de Serra Negra (MG). Goiânia: Editora da UFG, 1981, 124 p.

CHRISTOFOLETTI, A. Geomorfologia Fluvial. São Paulo: Edgard Blücher, 1980. 313 p.

Aplicabilidade do Conhecimento Geomorfológico nos Projetos de Planejamento. In: GUERRA, A J. T.; CUNHA, S. B. (Org.). Geomorfologia: uma atualização de bases e conceitos. $4^{\mathrm{a}}$ ed. Rio de Janeiro: Bertrand Brasil, 2001. p 415-440.

FLORENZANO, T. G.. Cartografia. In: FLORENZANO, T. G. (Org.) Geomorfologia conceitos e tecnologias atuais. São Paulo: Oficina de Textos, 2008. p. 105-128.

GREGORY, K. J. A Natureza da Geografia Física. Tradução de Eduardo de Almeida Navarro. Rio de Janeiro: Bertrand Brasil, 1992. 367 p.
INSTITUTO BRASILEIRO DE GEOGRAFIA E ESTATÍSTICA(IBGE). Diretoria de Serviços Geográfico. Porto Alegre: Primeira Diretoria de Levantamento, 1977.

LUPINACCI, C. M., MENDES, I. A., SANCHEZ, M. S. A Cartografia do Relevo: Uma Análise Comparativa de Técnicas de Gestão Ambiental. Revista Brasileira de Geomorfologia, Ano 4, n 1, UGB, 2003, p 1-9.

MÜLLER FILHO, I. L. Notas para o Estudo de Geomorfologia do Rio Grande do Sul, Brasil. Publicação Especial n. 1. Santa Maria: Imprensa Universitária. UFSM. 1970.

PENTEADO-ORELHANA, M. M. Metodologia Integrada no Estudo do Meio Ambiente. Geografia, Rio Claro, v. 10, n.20, out. 1985. p. 125-148.

ROBAINA, L. E. S.; TRENTIN, R., BAZZAN, T., RECKZIEGEL, E. W., DE NARDIN, D.; VERDUM, R. Compartimentação Geomorfológica da Bacia Hidrográfica do Ibicuí, Rio Grande do Sul, Brasil: Proposta de Classificação. Revista Brasileira de Geomorfologia . v.11 n.2, 2010. p. $11-23$.

RODRIGUES, S. C.; BRITO, J. L. S. Mapeamento Geomorfológico de Detalhe-Uma Proposta de Associação entre o Mapeamento Tradicional e as Novas Técnicas em Geoprocessamento. Caminhos de Geografia, Uberlândia: UFU. n. 1. 2000. p. 1 -6.

ROSS, J. L. S. Geomorfologia. Ambiente e Planejamento. São Paulo: Contexto, 1990.

O Registro Cartográfico dos Fatos Geomorfológicos e a Questão da Taxonomia do Relevo. Revista do Departamento de Geografia, São Paulo; USP, Nº, 1992. 
ROSS, J. L. S.; MOROZ, I. C. Mapa geomorfológico do Estado de São Paulo. Revista do Departamento de Geografia, São Paulo, n.10, p.41-56, 1996.

SANTOS, L. J. C.; OKA-FIORI, C.; CANALLI, N, E. FIORI, A. P. SILVEIRA, C. T. SILVA, J. M. F.; ROSS, J. L. S. Mapeamento geomorfológico do estado do Paraná. Revista Brasileira de Geomorfologia. n. 2 , 2006. p. $03-12$.

SILVA. J. M. F.; SANTOS, L. J. C. Fácies Pedológicas Associadas à Planicies Fluviais: Estudo na Porção Norte da Serra do Mar Paranaense. Caminhos de Geografia, Uberlândia: UFU. V.12, n. 37. 2010. p. 54-64. 